\title{
Age-related hyperkyphosis, independent of spinal osteoporosis, is associated with impaired mobility in older community-dwelling women
}

\author{
W. B. Katzman • E. Vittinghoff • D. M. Kado
}

Received: 14 November 2009 / Accepted: 9 March 2010/Published online: 18 May 2010

(C) The Author(s) 2010. This article is published with open access at Springerlink.com

\begin{abstract}
Summary While many assume hyperkyphosis reflects underlying spinal osteoporosis and vertebral fractures, our results suggest hyperkyphosis is independently associated with decreased mobility. Hyperyphosis is associated with slower Timed Up and Go performance times and may be a useful clinical marker signaling the need for evaluation of vertebral fracture and falling risk.

Introduction While multiple studies have demonstrated negative effects of hyperkyphosis on physical function, none have disentangled the relationship between hyperkyphosis, impaired function, and underlying spinal osteoporosis. The purpose of this study is to determine whether kyphosis, independent of spinal osteoporosis, is associated with mobility on the Timed Up and Go, and to quantify effects of other factors contributing to impaired mobility. Methods We used data for 3,108 community-dwelling women aged 55-80 years in the Fracture Intervention Trial. All participants had measurements of kyphosis, mobility
\end{abstract}

This research was supported by the UCSF-Kaiser Building Interdisciplinary Research Careers in Women's Health (BIRCWH) and cofunded by the National Institute of Child Health and Human Development (NICHD) and the Office of Research on Women's Health (ORWH) 5 K12 HD052163.

W. B. Katzman $(\bowtie)$

University of California, San Francisco,

UCSF Box 0625, San Francisco, CA 94143-0625, USA

e-mail: wendy.katzman@ucsfmedctr.org

E. Vittinghoff

Epidemiology and Biostatistics, University of California,

San Francisco, CA, USA

D. M. Kado

University of California,

Los Angeles, CA, USA time on the Timed Up and Go test, height, weight, total hip bone mineral density (BMD), grip strength, and vertebral fractures at baseline visits in 1993. Demographic characteristics included age and smoking status. We calculated mean Timed Up and Go time by quartile of kyphosis. Using multivariate linear regression, we estimated the independent association of kyphosis with mobility time, and quantified effects of other covariates on mobility.

Results Mean mobility time increased from $9.3 \mathrm{~s}$ in the lowest to $10.1 \mathrm{~s}$ in the highest quartile of kyphosis. In a multivariate-adjusted model, mobility time increased $0.11 \mathrm{~s}$ $(p=0.02)$ for each standard deviation $\left(11.9^{\circ}\right)$ increase in kyphosis. Longer performance times were significantly associated with increasing age, decreasing grip strength, vertebral fractures, body mass index $\geq 25$, and total hip BMD in the osteoporotic range.

Conclusions Kyphosis angle is independently associated with decreased mobility on the Timed Up and Go, which is in turn correlated with increased fall risk. Hyperkyphosis may be a useful clinical marker signaling the need for evaluation of vertebral fracture and falling risk.

Keywords Hyperkyphosis · Impaired mobility · Kyphosis · Spinal osteoporosis

\section{Introduction}

Age-related hyperkyphosis is an exaggerated anterior curvature of the thoracic spine. Older adults with hyperkyphosis are at increased risk for impaired physical function [1-6], falls [7], and fractures [8]. While multiple studies have demonstrated a negative effect of hyperkyphosis on physical function $[1,3,5,6,9,10]$, none have been able to disentangle whether the impaired function might be explained by 
another associated predictor underlying spinal osteoporosis [11]. Furthermore, these studies have been limited by small sample sizes [3], qualitative measures of kyphosis [1, 5], or lack of control of confounding variables $[1,3,9,10]$.

As impaired physical function itself is associated with fall risk and fractures, further examination of the relationship between kyphosis and measured physical function might inform other treatment strategies to forestall or even prevent functional decline. Currently, physicians often will refer patients to physical therapy for problems with balance and gait, but there are few referrals for hyperkyphosis. The association between hyperkyphosis and advanced age, decreased grip strength, low bone mineral density, and vertebral compression fractures $[1,5,12-16]$, that themselves can impact on physical function, may serve to downplay the importance of age-related postural change. As an example, even though only $36-37 \%$ of older persons with the worst degrees of kyphosis have underlying vertebral fractures [13, 17], most clinicians assume vertebral fractures are the cause of hyperkyphosis, and may therefore consider it an incidental finding rather than an important clinical condition worthy of treatment itself $[18,19]$. Establishing hyperkyphosis as a significant predictor of impaired mobility, independent of other significant predictors likely to impair mobility, could help justify intervention to reduce or delay progression of hyperkyphosis. Currently, interventions targeting easily modifiable impairments that contribute to kyphosis progression [20-27], including exercise and bracing, are not widely used.

Using data for 3,108 older women in the Fracture Intervention Trial (FIT), we sought to determine whether angle of kyphosis, independent of spinal osteoporosis and other factors, is associated with mobility as measured by performance times on the Timed Up and Go, an objective test used to identify people at risk for future falls, and to quantify the effects of other factors contributing to impaired mobility.

\section{Methods}

\section{Overview}

The FIT was a randomized, controlled multicenter trial among 6,459 women with osteopenia or osteoporosis who were randomized to alendronate or placebo to test the efficacy of alendronate for reduction of risk of osteoporotic fractures [28]. Women randomized to the placebo arm of FIT, including women with and without vertebral fracture, were included in these analyses [29].

\section{Subjects}

Women included in FIT were required to be 55-80 years of age, post-menopausal for at least 2 years, live independently in the community, and have a bone mineral density (BMD) of the femoral neck 1.6 or more standard deviations (SD) below peak premenopausal femoral neck BMD (less than $0.68 \mathrm{~g} / \mathrm{cm}^{2}$ ). Of the 3,223 women in the placebo arm of FIT 3,108 women with complete data were included in our analyses. By design, one third of the women randomized to the placebo arm of the study had prevalent fractures at baseline.

\section{Measurements}

All participants had measurements of kyphosis, mobility, height, weight, BMD of the hip, grip strength, and vertebral fractures at baseline visits in 1993. Basic demographic characteristics included age and smoking status, classified as never smoked, previous smoker, or current smoker.

Kyphosis angle was measured using a Debrunner Kyphometer (Proteck AG, Bern, Switzerland), a protractor-like instrument. The arms of the device are placed over the spinous process of $\mathrm{C} 7$ superiorly and $\mathrm{T} 12$ inferiorly [15]. This measurement of kyphosis angle has excellent reliability and repeatability (intra-rater and interrater correlation coefficients both 0.91 , and coefficient of variation for repeated measurements $=8.4 \%$ ) [30].

The Timed Up and Go is a widely used clinical tool for detecting mobility impairments in older adults. This test measures the time to rise from a $48 \mathrm{~cm}$ height armchair, walk $3 \mathrm{~m}$, turn and return to a fully seated position in the chair [31]. This test has excellent reliability (ICC 0.91-0.96) [32], and times $\geq 12 \mathrm{~s}$ have high sensitivity and specificity for identifying elderly individuals at risk for mobility impairments and falls [32, 33].

Body mass index (BMI) was calculated from the height and weight measurements using a standard formula weight $(\mathrm{kg}) /[\text { height }(\mathrm{m})]^{2}$. Bone mineral density was measured using the QDR 2000 (Hologic, Inc., Waltham, MA, USA). Quality control measures have been detailed elsewhere [34]. Grip strength was measured with a handheld dynamometer according to standardized protocol. Vertebral fractures were assessed using a standardized digitization and semi-quantitative classification method from lateral radiographs of the thoracic and lumbar spine that has been described previously [34]. A fracture was defined as any deformity in vertebral height ratio exceeding three standard deviations below the mean of normal [34].

\section{Statistical analyses}

We first calculated mean Timed Up and Go performance times, measured in seconds, by quartile of kyphosis. We then used a multiple linear regression model to estimate the independent association of angle of kyphosis with performance times, and to quantify the effects of other covariates on this measure of mobility, including age, smoking status, body 
mass index, total BMD of the hip, grip strength, and number of vertebral fractures. We categorized body mass index according to Center for Disease Control categories $(<18.5=$ underweight, 18.5-24.9=normal, 25-29.9=overweight and $\geq 30=$ obese), and BMD according to the World Health Organization cutoff values for osteopenia using total hip BMD measurements from Hologic equipment (total hip BMD $<0.637 \mathrm{~g} / \mathrm{m}^{2}=$ osteoporosis, $0.637-0.820 \mathrm{~g} / \mathrm{m}^{2}=$ osteopenia, and $>0.820 \mathrm{~g} / \mathrm{m}^{2}=$ normal).

\section{Results}

Women were an average of 68.2 years old, and ranged from 55 to 81 years old (Table 1). All were independently living, ambulatory, and $95 \%$ rated their health as good to excellent. Mean (SD) kyphosis angle was $47.6(11.9)^{\circ}$ (range 3-83 ${ }^{\circ}$ ), and was associated with increasing age, higher body mass index, lower total hip BMD, lower grip strength, and history of vertebral fracture. Mean (SD) performance on the Timed Up and Go was 9.7 (2.7)s (range 5-91 s). Figure 1 shows mean performance times by quartile of kyphosis angle. In a model adjusting only for age, the increase in average performance time for each standard deviation $\left(11.9^{\circ}\right)$ increase in kyphosis angle was $0.2 \mathrm{~s}(p<0.001)$.

Table 1 Baseline characteristics of 3,108 subjects in the placebo arm of the Fracture Intervention Trial (FIT)

\begin{tabular}{ll}
\hline & Mean (SD) or percent \\
\hline Kyphosis (degs) & $47.6(11.9)$ \\
Age (years) & $68.2(6.1)$ \\
Smoking & \\
Never & $54 \%$ \\
Smoked in past & $35 \%$ \\
Current smoker & $11 \%$ \\
Body mass index & \\
$<18.5=$ underweight & $2 \%$ \\
$18.5 / 24.999=$ normal & $52 \%$ \\
$25 / 29.999=$ overweight & $34 \%$ \\
$>30=$ obese & $12 \%$ \\
Total hip BMD $\left(\mathrm{g} / \mathrm{m}^{2}\right)$ & \\
$<0.637 \mathrm{~g} / \mathrm{m}^{2}=$ osteoporosis & $25 \%$ \\
$0.637-0.820 \mathrm{~g} / \mathrm{m}^{2}=$ osteopenia & $69 \%$ \\
$>0.820 \mathrm{~g} / \mathrm{m}^{2}=$ normal) & $6 \%$ \\
Grip strength $(\mathrm{kgs})$ & $23.7(5.1)$ \\
Number of vertebral fx at baseline $(n)$ & \\
0 & $70 \%$ \\
1 & $20 \%$ \\
2 & $10 \%$
\end{tabular}

$\mathrm{S} D$ standard deviation, degs degrees, $\mathrm{g} / \mathrm{m}^{2}$ grams per meter squared; $\mathrm{kgs}$ kilograms, $n$ number
The association between kyphosis and longer times was attenuated but remained statistically significant after controlling for age, smoking status, body mass index, total BMD of the hip, grip strength, and number of vertebral fractures (Table 2). Longer performance times were also strongly associated with increasing age and decreasing grip strength; in addition, there was weak evidence for reduced mobility among current smokers and women with vertebral fractures. Compared to women with normal BMI, average performance times were longer among women in the overweight and obese categories. Mobility was also reduced among women with total hip $\mathrm{BMD}$ in the osteoporotic range, as compared to women with normal hip BMD.

\section{Discussion}

We found that kyphosis angle is a significant independent contributor to mobility impairment as assessed by the Timed Up and Go in both age-adjusted and multivariateadjusted models. Our findings substantiate prior research showing that decreased mobility is associated with advancing age, muscle weakness, low bone density, and history of vertebral fracture [18, 19, 35]; however, distinct from previous studies, we found that hyperkyphosis is a significant contributor to mobility impairment independent of underlying low bone density and vertebral fractures that are often assumed to be the causative factors of ill health.

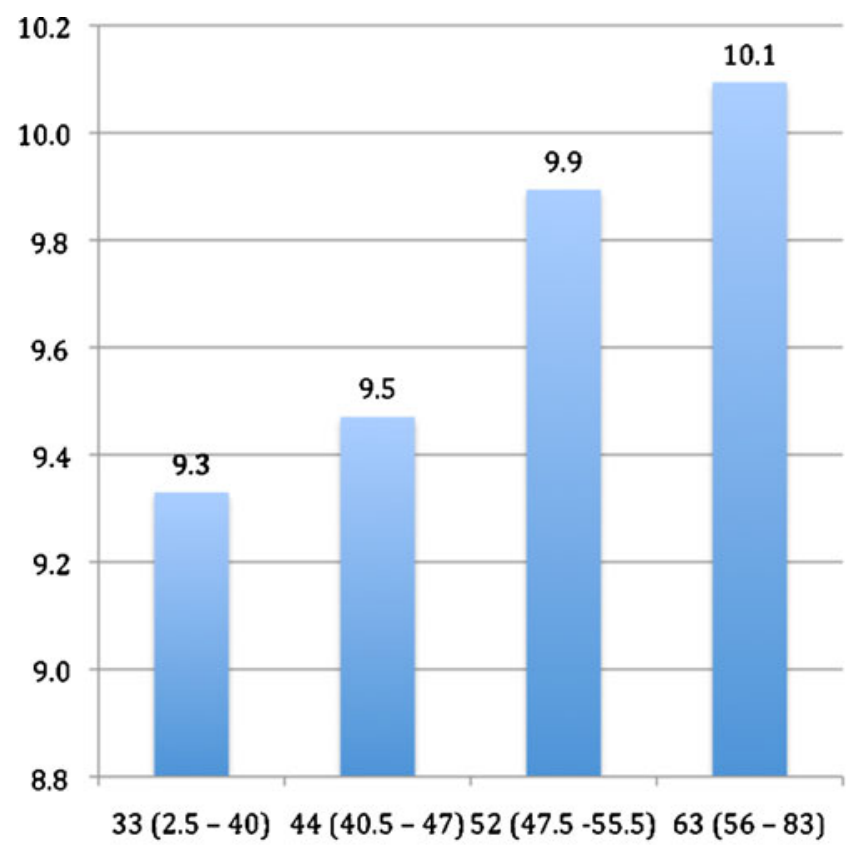

secs $=$ seconds; degs $=$ degrees; $\min -\max =$ minimum-maximum

Fig. 1 Timed Up and Go $(s)$ by Quartile of Kyphosis $\left({ }^{\circ}\right)$ (min-max) 
Table 2 Predictors of impaired mobility

CI 95\% confidence interval, yrs years, $S D$ standard deviation, $n$ number

\begin{tabular}{llc}
\hline Variable & $\begin{array}{l}\text { Increase in performance times on Timed } \\
\text { Up and Go (s) }(95 \% \mathrm{CI})\end{array}$ & $p$ value \\
\hline Kyphosis (per SD) & $0.11(0.02,0.21)$ & 0.02 \\
Age (per 5 yrs) & $0.46(0.38,0.54)$ & $<0.0001$ \\
Smoking & & - \\
Non-smoker & Reference & 0.15 \\
Former smoker & $-0.14(-0.34,0.05)$ & 0.09 \\
Current smoker & $0.26(-0.04,0.57)$ & \\
& & 0.92 \\
Body mass index & $0.03(-0.65,0.72)$ & - \\
Underweight & Reference & $<0.0001$ \\
Normal & $0.47(0.27,0.68)$ & $<0.0001$ \\
Overweight & $1.23(0.93,1.53)$ & - \\
Obese & & 0.81 \\
Total hip BMD & Reference & 0.015 \\
Normal & $0.05(-0.35,0.45)$ & $<0.0001$ \\
Osteopenic & $0.55(0.11,0.99)$ & 0.003 \\
Osteoporotic & $-0.23(-0.32,-0.13)$ & \\
Grip strength (per SD) & & Reference \\
Vertebral fractures $(n)$ & $0.16(-0.08,0.39)$ & \\
None & $0.49(0.17,0.82)$ & \\
1 &
\end{tabular}

Performance times on the Timed Up and Go increased from a mean $9.3 \mathrm{~s}$ in the lowest quartile of kyphosis to a mean of $10.1 \mathrm{~s}$ in the highest quartile of kyphosis. The fourth quartile mean was longer than the upper limit of normal based on data for 4,395 adults aged 60-99 years, and is indicative of worsethan-average mobility [36]. However, the adjusted increase in average performance times for each standard deviation $\left(11.9^{\circ}\right)$ increase in kyphosis angle was a modest $0.11 \mathrm{~s}$, comparable to expected increase in performance time over 1 year.

The association of hyperkyphosis with impaired mobility may in part be explained by its impact on the body's center of mass, which in turn affects body sway, gait steadiness, and risk for falls [37]. Hyperkyphosis also restricts pulmonary capacity [16, 38-41], which can interfere with normal physical function and ultimately increases risk of mortality [42].

While hyperkyphosis is easily clinically identifiable, body mass index, grip strength, and especially BMD are more difficult to measure, suggesting that significant hyperkyphosis could serve as a signal for further evaluation, including a check for undetected vertebral fractures and an evaluation of fall risk. In addition, exercise regimens and bracing that have been shown to reduce hyperkyphosis may also be appropriate [20-27]. Our results suggest that treating hyperkyphosis may help preserve mobility, although further work is needed to determine whether reducing hyperkyphosis alone can slow mobility decline.

\section{Limitations}

The primary limitation of our study is the cross-sectional nature of this analysis, which does not allow us to infer causality. The strengths of our study include the large sample size and measurement of kyphosis angle, Timed Up and Go performance times, and potential confounders of their association, including BMD, grip strength, and vertebral fracture. Furthermore, using an objective measure of physical function that is a validated predictor of increased fall risk allows us to demonstrate a more clinically meaningful outcome rather than merely report a significant association. Finally, we were able to disentangle the ill effects of spinal osteoporosis from that of hyperkyphosis. Until recently, many have assumed that hyperkyphosis is simply a reflection of underlying vertebral fractures; our results suggest that hyperkyphosis itself is deserving of more clinical attention.

\section{Conclusions}

Kyphosis angle is independently associated with decreased mobility, which is in turn correlated with increased fall risk. Hyperkyphosis may be a useful clinical marker signaling the need for evaluation of vertebral fracture and falling risk. 
While exercises and bracing that can reduce hyperkyphosis are available, further work is needed to show that reducing hyperkyphosis helps preserve mobility and reduces falling risk.

Acknowledgement All of the authors had access to the data and participated in writing the manuscript.

\section{Conflicts of interest None}

Open Access This article is distributed under the terms of the Creative Commons Attribution Noncommercial License which permits any noncommercial use, distribution, and reproduction in any medium, provided the original author(s) and source are credited.

\section{References}

1. Balzini L, Vannucchi L, Benvenuti F et al (2003) Clinical characteristics of flexed posture in elderly women. J Am Geriatr Soc 51(10):1419-1426

2. Sinaki M, Brey RH, Hughes CA, Larson DR, Kaufman KR (2005) Balance disorder and increased risk of falls in osteoporosis and kyphosis: significance of kyphotic posture and muscle strength. Osteoporos Int 16(8):1004-1010

3. Ryan SD, Fried LP (1997) The impact of kyphosis on daily functioning. J Am Geriatr Soc 45(12):1479-1486

4. Lyles KW, Gold DT, Shipp KM, Pieper CF, Martinez S, Mulhausen PL (1993) Association of osteoporotic vertebral compression fractures with impaired functional status. Am J Med 94(6):595-601

5. Kado DM, Huang MH, Barrett-Connor E, Greendale GA (2005) Hyperkyphotic posture and poor physical functional ability in older community-dwelling men and women: the Rancho Bernardo study. J Gerontol A Biol Sci Med Sci 60(5):633-637

6. Schenkman M, Shipp KM, Chandler J, Studenski SA, Kuchibhatla M (1996) Relationships between mobility of axial structures and physical performance. Phys Ther 76(3):276-285

7. Kado DM, Huang MH, Nguyen CB, Barrett-Connor E, Greendale GA (2007) Hyperkyphotic posture and risk of injurious falls in older persons: the Rancho Bernardo Study. J Gerontol A Biol Sci Med Sci 62(6):652-657

8. Huang MH, Barrett-Connor E, Greendale GA, Kado DM (2006) Hyperkyphotic posture and risk of future osteoporotic fractures: the Rancho Bernardo study. J Bone Miner Res 21(3):419-423

9. Hirose D, Ishida K, Nagano Y, Takahashi T, Yamamoto H (2004) Posture of the trunk in the sagittal plane is associated with gait in community-dwelling elderly population. Clin Biomech (Bristol, Avon) 19(1):57-63

10. Takahashi T (2005) Trunk deformity is associated with a reduction in outdoor activites of daily living and life satisfaction in community-dwelling older people. Osteoporos Int 16:273-279

11. Nevitt MC, Ettinger B, Black DM et al (1998) The association of radiographically detected vertebral fractures with back pain and function: a prospective study. Ann Intern Med 128(10):793-800

12. Kado DM, Duong T, Stone KL et al (2003) Incident vertebral fractures and mortality in older women: a prospective study. Osteoporos Int 14(7):589-594

13. Kado DM, Browner WS, Palermo L, Nevitt MC, Genant HK, Cummings SR (1999) Vertebral fractures and mortality in older women: a prospective study. Study of Osteoporotic Fractures Research Group. Arch Intern Med 159(11):1215-1220
14. Ettinger B, Black DM, Palermo L, Nevitt MC, Melnikoff S, Cummings SR (1994) Kyphosis in older women and its relation to back pain, disability and osteopenia: the study of osteoporotic fractures. Osteoporos Int 4(1):55-60

15. Ensrud KE, Black DM, Harris F, Ettinger B, Cummings SR (1997) Correlates of kyphosis in older women. The Fracture Intervention Trial Research Group. J Am Geriatr Soc 45(6):682-687

16. Lombardi I Jr, Oliveira LM, Monteiro CR, Confessor YQ, Barros TL, Natour J (2004) Evaluation of physical capacity and quality of life in osteoporotic women. Osteoporos Int 15(1):80-85

17. Schneider DL, von Muhlen D, Barrett-Connor E, Sartoris DJ (2004) Kyphosis does not equal vertebral fractures: the Rancho Bernardo study. J Rheumatol 31(4):747-752

18. Brown M, Sinacore DR, Binder EF, Kohrt WM (2000) Physical and performance measures for the identification of mild to moderate frailty. J Gerontol A Biol Sci Med Sci 55(6):M350-M355

19. Lindsey C, Brownbill RA, Bohannon RA, Ilich JZ (2005) Association of physical performance measures with bone mineral density in postmenopausal women. Arch Phys Med Rehabil 86 (6): 1102-1107

20. Benedetti MG, Berti L, Presti C, Frizziero A, Giannini S (2008) Effects of an adapted physical activity program in a group of elderly subjects with flexed posture: clinical and instrumental assessment. J Neuroeng Rehabil 5:32

21. Greendale GA, Huang MH, Karlamangla AS, Seeger L, Crawford S (2009) Yoga decreases kyphosis in senior women and men with adult-onset hyperkyphosis: results of a randomized controlled trial. J Am Geriatr Soc 57(9):1569-1579

22. Katzman WB, Sellmeyer DE, Stewart AL, Wanek L, Hamel KA (2007) Changes in flexed posture, musculoskeletal impairments, and physical performance after group exercise in community-dwelling older women. Arch Phys Med Rehabil 88(2):192-199

23. Pawlowsky SB, Hamel KA, Katzman WB (2009) Stability of kyphosis, strength, and physical performance gains 1 year after a group exercise program in community-dwelling hyperkyphotic older women. Arch Phys Med Rehabil 90(2):358-361

24. Itoi E, Sinaki M (1994) Effect of back-strengthening exercise on posture in healthy women 49 to 65 years of age. Mayo Clin Proc 69(11):1054-1059

25. Renno RACMGR, Driusso P, Costa D, Oishi J (2005) Effects of an exercise programon respiratory functon, posture, and onquality-of-life in osteoporotic women: a pilot study. Physiotherapy $91: 113-118$

26. Pfeifer M, Begerow B, Minne HW (2004) Effects of a new spinal orthosis on posture, trunk strength, and quality of life in women with postmenopausal osteoporosis: a randomized trial. Am J Phys Med Rehabil 83(3):177-186

27. Bautmans I, Van Arken J, Van Mackelenberg M, Mets T (2010) Rehabilitation using manual mobilization for thoracic kyphosis in elderly postmenopausal patients with osteoporosis. J Rehabil Med 42(2):129-135

28. Black DM, Cummings SR, Karpf DB et al (1996) Randomised trial of effect of alendronate on risk of fracture in women with existing vertebral fractures. Fracture Intervention Trial Research Group. Lancet 348(9041):1535-1541

29. Cummings SR, Black DM, Thompson DE et al (1998) Effect of alendronate on risk of fracture in women with low bone density but without vertebral fractures: results from the Fracture Intervention Trial. JAMA 280(24):2077-2082

30. Ohlen G, Spangfort E, Tingvall C (1989) Measurement of spinal sagittal configuration and mobility with Debrunner's kyphometer. Spine 14(6):580-583

31. Podsiadlo D, Richardson S (1991) The timed "Up \& Go": a test of basic functional mobility for frail elderly persons. J Am Geriatr Soc 39(2):142-148 
32. Bischoff HA, Stahelin HB, Monsch AU et al (2003) Identifying a cut-off point for normal mobility: a comparison of the timed 'up and go' test in community-dwelling and institutionalised elderly women. Age Ageing 32(3):315-320

33. Shumway-Cook A, Brauer S, Woollacott M (2000) Predicting the probability for falls in community-dwelling older adults using the Timed Up \& Go Test. Phys Ther 80(9):896-903

34. Black DM, Reiss TF, Nevitt MC, Cauley J, Karpf D, Cummings SR (1993) Design of the Fracture Intervention Trial. Osteoporos Int 3(Suppl 3):S29-S39

35. Fried LP, Tangen CM, Walston J et al (2001) Frailty in older adults: evidence for a phenotype. J Gerontol A Biol Sci Med Sci 56(3):M146-M156

36. Bohannon RW (2006) Reference values for the timed up and go test: a descriptive meta-analysis. J Geriatr Phys Ther 29(2): 64-68

37. Sinaki M, Brey RH, Hughes CA, Larson DR, Kaufman KR (2005) Significant reduction in risk of falls and back pain in osteoporotic-kyphotic women through a Spinal Proprioceptive
Extension Exercise Dynamic (SPEED) program. Mayo Clin Proc 80(7):849-855

38. Di Bari M, van de Poll-Franse LV, Onder G et al (2004) Antihypertensive medications and differences in muscle mass in older persons: the Health, Aging and Body Composition Study. J Am Geriatr Soc 52(6):961-966

39. Culham EG, Jimenez HA, King CE (1994) Thoracic kyphosis, rib mobility, and lung volumes in normal women and women with osteoporosis. Spine (Phila Pa 1976) 19(11):1250-1255

40. Schlaich C, Minne HW, Bruckner T et al (1998) Reduced pulmonary function in patients with spinal osteoporotic fractures. Osteoporos Int 8(3):261-267

41. Leech JA, Dulberg C, Kellie S, Pattee L, Gay J (1990) Relationship of lung function to severity of osteoporosis in women. Am Rev Respir Dis 141(1):68-71

42. Kado DM, Huang MH, Karlamangla AS, Barrett-Connor E, Greendale GA (2004) Hyperkyphotic posture predicts mortality in older community-dwelling men and women: a prospective study. J Am Geriatr Soc 52(10):1662-1667 